\title{
Investigating differential protective effects of marriage on substance use by sexual identity status
}

\author{
Karen F. Trocki ${ }^{1}$, Amy A. Mericle ${ }^{1}$, Laurie A. Drabble ${ }^{1,2}$, Jamie L. Klinger ${ }^{1}$, Cindy B. Veldhuis ${ }^{3}$, Tonda L. \\ Hughes $^{3}$, Katherine J. Karriker-Jaffe ${ }^{a}$
}

${ }^{1}$ Alcohol Research Group, Public Health Institute, 6001 Shellmound St., Suite 450, Emeryville, CA 94608, USA2

${ }^{2}$ San José State University College of Health and Human Sciences, One Washington Square, San Jose, CA 95192-0049, USA

${ }^{3}$ School of Nursing, Columbia University, 630 West 168th Street, Mail Box Code 6, New York, NY 10032, USA

\begin{abstract}
Background: Research suggests that marriage is protective against substance use. However, few studies have examined whether this protective effect differs for sexual minorities, a population at increased risk for substance use. Using data from four waves of the cross-sectional U.S. National Alcohol Survey (NAS; 2000, 2005, 2010, and 2015), we investigated whether the protective effects of marriage varied by sexual identity.

Methods: Sex-stratified logistic regression models were used to examine independent and interactive effects of current marital status (being married vs. not) and sexual minority status (lesbian/gay/bisexual vs. heterosexual) on high-intensity drinking, alcohol use disorder, and marijuana use in the past year.

Results: Among both women and men, sexual minority status was generally associated with higher odds of these outcomes and marriage was consistently associated with lower odds. Differential effects of marriage by sexual identity with respect to marijuana use were found only among men; marriage was significantly associated with decreased odds of marijuana use among heterosexual men but increased odds among sexual minority men.

Conclusions: Marriage may be less consistently protective against hazardous drinking and marijuana use among sexual minorities than heterosexuals. Findings underscore the importance of both quantitative and qualitative studies designed to better understand disparities in substance use across both sexual identity and relationship statuses.
\end{abstract}

\section{Introduction}

Sexual minority individuals (e.g., lesbian, gay, and bisexual identified) report higher rates of hazardous drinking and marijuana use than heterosexuals, with differences more consistent and pronounced among women than men (Boyd, Veliz, Stephenson, Hughes, \& McCabe, 2019; Demant et al., 2016; Drabble, Mericle, Karriker-Jaffe, \& Trocki, 2020; Hughes, Wilsnack, \& Kantor, 2016; Kerridge et al., 2017; King et al., 2008). Minority stress has been identified as an important contributor to sexual-orientation-related disparities in health risk behaviors, including hazardous drinking and other substance use (Lewis, Mason, Winstead, Gaskins, \& Irons, 2016; Lewis, Winstead, Lau-Barraco, \& Mason, 2017; McCabe, Bostwick, Hughes, West, \& Boyd, 2010). The cumulative impact of stressors associated with interpersonal and institutional prejudice and discrimination, expectations of rejection, managing visibility of identity, and self-stigmatization increase the likelihood of psychological distress and mental health problems among sexual minority individuals (Frost, 2017; Hatzenbuehler, 2009; Meyer, 2003; Meyer \& Frost, 2013) and same-sex couples (Frost et al., 2017; LeBlanc \& Frost, 2019; LeBlanc, Frost, \& Bowen, 2018; LeBlanc, Frost, \& Wight, 2015; Rostosky \& Riggle, 2016).

Although sexual-orientation-related health disparities among adults are well-documented, there is a dearth of research examining factors that might buffer these risks (de Lira \& de Morais, 2018; Hughes, Veldhuis, Drabble, \& Wilsnack, 2020). Population-based research suggests that individuals who are married are less likely to engage in

Correspondence: Laurie A. Drabble

Email: laurie.drabble@sjsu.edu

Financial support: Research reported in this publication was supported by the National Institute on Drug Abuse of the National Institutes of Health under Grant number R01DA036606 and National Institute on Minority Health and Health Disparities of the National Institutes of Health under Award Number R03MD011481 (Trocki and Drabble PI) as well as the National Institute on Alcohol Abuse and Alcoholism under Grant number P50, AA005595 (Greenfield PI). Dr. Hughes is supported by R01 AA013328-14 (PI: T. Hughes) National Institute on Alcohol Abuse and Alcoholism (NIAAA). Dr. Veldhuis' participation in this research was made possible through an NIH/NIAAA Ruth Kirschstein Postdoctoral Research Fellowship (F32AA025816; PI C. Veldhuis).

Declaration of interest: None

Keywords: substance use, high-intensity drinking, alcohol use disorder, marijuana use, sexual minorities 
hazardous drinking or to use marijuana than those who are not, including those who are cohabiting, single, or divorced/separated (Blair \& Menasco, 2016; Jang, Patrick, \& Schuler, 2018; Kahle, Veliz, McCabe, \& Boyd, 2020; Li, Wilsnack, Wilsnack, \& Kristjanson, 2010; Liang \& Chikritzhs, 2012; Reczek, Liu, \& Spiker, 2014). Protective effects of marriage are linked to a variety of factors, including marital partners' influences on each other's health habits, greater social support, and lower general stress (Umberson \& Karas Montez, 2010). Yet little research has investigated the potential protective effects of marriage among sexual minorities.

Expanded access to same-sex marriage affords an opportunity for research to explore whether and how legal marriage may confer protective effects among sexual minorities (Umberson \& Kroeger, 2016). Legal recognition of same-sex marriage (marriage equality) began at the state level in the U.S. in 2003, and 37 of the 50 states had established same-sex marriage rights by the time the U.S. Supreme Court decision mandated national marriage equality in June 2015. Even before 2015, many same-sex couples who were legally married in another state or country considered themselves to be married, even if the state in which they lived did not recognize their marriage (DeMaio, Bates, \& O'Connell, 2013). Policy changes, such as national legalization of marriage for same-sex couples, may reduce sexual minority stigma and experiences of minority stress (Herek, 2006; Ogolsky, Monk, Rice, \& Oswald, 2019a; Rostosky \& Riggle, 2016; Tatum, 2017). Studies about the potential impacts of legal marriage are needed to better understand how being married may or may not reduce sexual-orientation-related disparities in substance use outcomes.

Marriage equality extends access to various psychological and material benefits of marriage to same-sex couples (Herek, 2006; Riggle, Wickham, Rostosky, Rothblum, \& Balsam, 2017). Qualitative and mixed methods studies have identified a number of specific reasons that legal marriage may contribute to improved health outcomes among sexual minorities. First, legal marriage provides a sense of social inclusion and acceptance for sexual minorities (Badgett, 2011; Ramos, Goldberg, \& Badgett, 2009; Rostosky, Riggle, Rothblum, \& Balsam, 2016; Shulman, Gotta, \& Green, 2012) Second, legal marriage may have a positive impact on how immediate family members and extended social networks recognize and affirm the committed relationships of sexual minorities (Lannutti, 2008, 2014; Ogolsky, Monk, Rice, \& Oswald, 2019b). Third, legal marriage provides access to important legal protections and financial benefits, which increases family security and a sense of entitlement to equal treatment (Lannutti, 2005, 2011b; MacIntosh, Reissing, \& Andruff, 2010; Rostosky et al., 2016). Finally, access to legal marriage may make it safer for sexual minorities to be open about their identity and relationships (MacIntosh et al., 2010; Riggle et al., 2017). At the same time, studies also document ambivalence or concerns about the potential unintended negative impacts on sexual minority communities and queer culture of centering marriage as an institution. For example, some sexual minority people are concerned that a focus on marriage rights over-emphasizes assimilation to heterosexual norms at the expense of broader community connections and social support for a wide range of relationship structures (Bosley-Smith \& Reczek, 2018; Drabble, Wootton, et al., 2020; Lannutti, 2011b; Ocobock, 2018).

Although the social and psychological meaning of marriage and intimacy are similar among sexual minorities and heterosexuals (Frost \& Gola, 2015), there are several factors that may differentially influence the protective effects of marriage among sexual minorities. Sexual minority couples may experience less social support than heterosexual couples from family and extended social networks, and more stigma-related stressors (Frost \& Gola, 2015; LeBlanc \& Frost, 2019; LeBlanc et al., 2018). At the same time, samesex couples report receiving more spousal support than different-sex couples, which may help buffer mental health consequences of discrimination (Donnelly, Robinson, \& Umberson, 2019). Dynamics of how couples influence one another's health behaviors may also differ by sexual identity (Umberson, Donnelly, \& Pollitt, 2018). These complexities highlight the importance of taking into account sexual identity in research that examines the potential protective effects of marriage on substance use.

An emerging body of research in the U.S. has examined how health risks may differ by marital status among sexual minorities. For example, several studies found that same-sex married or committed relationships are protective against psychological distress (Feinstein, Latack, Bhatia, Davila, \& Eaton, 2016; Riggle, Rostosky, \& Horne, 2010; Whitton, Dyar, Newcomb, \& Mustanski, 2018; Williams \& Fredriksen Goldsen, 2014) and may improve overall financial, psychological, and physical well-being (Ducharme \& Kollar, 2012). However, some of these studies are based on data from non-probability samples (Riggle et al., 2010; Whitton et al., 2018; Williams \& Fredriksen Goldsen, 2014), or rely on regional samples (Ducharme \& Kollar, 2012), which limits generalizability of findings. Furthermore, many studies of marriage and health among sexual minorities lack heterosexual comparison groups (Riggle et al., 2010; Whitton et al., 2018; Williams \& Fredriksen Goldsen, 2014).

Some studies on the protective effects of legalized same-sex relationships combine sexual minority women (SMW; e.g., lesbian and bisexual women) and sexual minority men (SMM; e.g., gay and bisexual men) in analyses (Feinstein et al., 2016; Riggle et al., 2010; Whitton et al., 2018; Williams $\&$ Fredriksen Goldsen, 2014). Because research suggests sex differences in the protective effects of marriage or relationship status (Blair \& Menasco, 2016; Li et al., 2010; Reczek, Pudrovska, Carr, Umberson, \& Thomeer, 2016), it is important to disaggregate analyses by sex to better understand how protective effects of marriage may vary for SMW and SMM. The importance of disaggregating by sex is underscored by research suggesting that married SMW may experience more microaggressions (Goldsen et al., 2017) and may benefit less from marriage (e.g., in relation to health care access and utilization) than sexual minority men (Carpenter, Eppink, Gonzales Jr, \& McKay, 2018). 
Although bisexuals in relationships with opposite-sex partners may "pass" as heterosexual and might be assumed to experience less minority stress, elevated risk for substance use and unique stressors in this population justify their inclusion in research related to potential protective effects of marriage. Research that disaggregates bisexual from monosexual groups (heterosexual and lesbian/gay) typically suggest similar or even greater risk of hazardous drinking and drug use among bisexual individuals (Gonzales, Przedworski, \& Henning-Smith, 2016; Hughes et al., 2020; McCabe, West, Strobbe, \& Boyd, 2018). Higher risks for hazardous drinking are also found among other groups who do not identify with strictly heterosexual or lesbian/gay/bisexual labels, including individuals who identify as "mostly heterosexual" (Hughes et al., 2010; Hughes, Wilsnack, \& Kristjanson, 2015) or "something else" (Eliason, Burke, van Olphen, \& Howell, 2011). Notably, elevated health risks appear to be consistent for individuals who identity as bisexual whether they are in same-sex or different-sex relationships (Hsieh \& Liu, 2019; Veldhuis et al., 2019). Bisexual individuals who are married to different-sex partners may be impacted by unique minority stressors that amplify risk of hazardous drinking and drug use (Arriaga \& Parent, 2019; Molina et al., 2015). For example, bisexual individuals in different-sex relationships often experience bi-negativity from both heterosexual and lesbian/gay communities (Arriaga \& Parent, 2019; Dyar, Feinstein, \& London, 2014; Lambe, Cerezo, \& O'Shaughnessy, 2017; Molina et al., 2015) and feel misrecognized or rendered invisible because of normative assumptions about sexuality being binary (Hayfield, Campbell, \& Reed, 2018). Studies of health across groups defined by marital status that operationalize sexual minority status by sex of marital partner typically exclude bisexual-identified individuals in relationships with different-sex partners, although this group appears to share patterns of hazardous drinking and drug use that are similar to those of other sexual minorities in same-sex relationships. Consequently, there is a need for research that defines bisexuals in both same and different-sex relationships as sexual minorities.

Findings from a few population-based studies have found protective effects for sexual minorities and heterosexuals in legally-recognized relationships compared to their single counterparts. These effects include better self-rated health (Reczek, Liu, \& Spiker, 2017), lower psychological distress (Wight, LeBlanc, \& Badgett, 2013), greater happiness (Wienke \& Hill, 2008), and fewer activity limitations (Spiker, Reczek, \& Liu, 2017). Differences in health risk behaviors by relationship status in these studies were more pronounced and variable among women than men (Reczek et al., 2017; Spiker et al., 2017). A recent study comparing marital advantage by sexual identity found the health advantage of marriage applied to heterosexual-identified women and men, but not to bisexual or lesbian/gay individuals (Hsieh \& Liu, 2019). Furthermore, bisexual women and men in different-sex married relationships had worse health outcomes (poorer self-reported health and more functional limitations) than those in same-sex married relationships (Hsieh \& Liu, 2019). Although research suggests that sexual identity is particularly salient in assessing risks for alcohol problems and marijuana use (McCabe, Hughes, Bostwick, West, \& Boyd, 2009; Midanik, Drabble, Trocki, \& Sell, 2006), few studies have examined whether sexual identity might modify the protective effect of marriage on alcohol or marijuana use.

Population-based studies that have examined whether the protective effect of marriage on alcohol use differs by sexual identity have yielded mixed results. For example, one recent U.S. study found marriage was associated with lower odds of alcohol use disorder and drug use disorder among heterosexual women and men, but not among SMW or SMM (Kahle et al., 2020). By contrast, other U.S. studies have found that both same-sex and different-sex married couples reported lower alcohol use than their cohabiting non-married counterparts (Reczek et al., 2014). Another study found that being married was associated with lower alcohol use among lesbian women but not gay men (Du Bois, Legate, \& Kendall, 2019). It is worth noting that the alcohol measures in two of these studies were limited. For example, in the studies by $\mathrm{Du}$ Bois and colleagues and Reczek and colleagues, heavy drinking was defined based on number of drinks (more than 7 drinks per week on average for women and 14 or more drinks per week for men). No measures of alcohol dependence or alcohol-related problems were included. Using a nationally-representative longitudinal sample of adults in Australia, Sabia and colleagues (2018) examined multiple health outcomes, including binge drinking, by partnership status (same-sex partner, differentsex cohabiting partner, different-sex spouse, no partner). Men in any partnered relationship reported less binge drinking than single men; however, among women, only those in a relationship with a different-sex partner were significantly less likely to report binge drinking than single women (Sabia, Wooden, \& Nguyen, 2018). To our knowledge, no studies have examined marijuana use by both sexual identity and marital status. Thus, the aim of the current study was to investigate the differential effects of marital status by sexual identity, stratified by sex, on heavy drinking, alcohol use disorder and marijuana use using data in a nationally-representative sample of U.S. adults.

\section{Materials and Methods}

Sample

Data were from four waves $(2000,2005,2010$, and 2015) of the National Alcohol Survey (NAS), a cross-sectional population-based survey of adults (ages 18 or older) in the U.S. The study included 29,571 respondents, and 25,510 respondents answered sexual identity questions, including 413 SMW and 421 SMM. See Table 1 for sample characteristics.

\section{Measures}

Marital Status. A dichotomous indicator of marital status was constructed: married (married and living with spouse, married and not living with spouse) vs not married (living as a couple in an unmarried relationship; legally separated; divorced; widowed; or never married). 
Sexual Identity. Sexual identity was assessed using a question that invited respondents to select the category that best fit their sexual identity. Given the small sample sizes of sexual minority subgroups, lesbian/bisexual women and gay/bisexual men were combined and compared to their respective heterosexual counterparts. In the 2015 survey, sexual identity response options also included "something else"; these respondents were categorized as sexual minority respondents.

Table 1

Sample Characteristics by Gender and Sexual Identity $(N=25,510)$

\begin{tabular}{|c|c|c|c|c|c|c|c|c|c|c|}
\hline & \multicolumn{4}{|c|}{ Women $(\mathrm{N}=14,395)$} & & \multicolumn{4}{|c|}{$\operatorname{Men}(\mathrm{N}=11,115)$} & \\
\hline & \multicolumn{2}{|c|}{$\begin{array}{l}\text { Heterosexual } \\
(\mathrm{N}=13,982)\end{array}$} & \multicolumn{2}{|c|}{$\begin{array}{c}\text { SMW } \\
(\mathrm{N}=413)\end{array}$} & & \multicolumn{2}{|c|}{$\begin{array}{c}\text { Heterosexual } \\
(\mathrm{N}=10,694)\end{array}$} & \multicolumn{2}{|c|}{$\begin{array}{l}\text { SMM } \\
(\mathrm{N}=421)\end{array}$} & \\
\hline & $\mathrm{n}$ & $\%$ & $\mathrm{n}$ & $\%$ & & $\mathrm{n}$ & $\%$ & $\mathrm{n}$ & $\%$ & \\
\hline Married & & & & & $* * *$ & & & & & $* * *$ \\
\hline No & 7,360 & 44.5 & 320 & 75.8 & & 4,369 & 38.0 & 360 & 82.8 & \\
\hline Yes & 6,579 & 55.5 & 93 & 24.3 & & 6,298 & 62.0 & 61 & 17.2 & \\
\hline Age & & & & & $* * *$ & & & & & \\
\hline $18-39$ & 4,271 & 39.2 & 190 & 60.5 & & 3,982 & 43.1 & 163 & 49.2 & \\
\hline $40+$ & 9,398 & 60.8 & 218 & 39.5 & & 6,601 & 57.0 & 257 & 50.8 & \\
\hline Children in the Household & & & & & & & & & & $* * *$ \\
\hline No & 8,690 & 59.7 & 288 & 66.1 & & 6,833 & 62.5 & 377 & 84.8 & \\
\hline Yes & 5,264 & 40.3 & 124 & 33.9 & & 3,838 & 37.5 & 44 & 15.2 & \\
\hline Race/Ethnicity & & & & & & & & & & $*$ \\
\hline White/Caucasian & 7,957 & 71.1 & 215 & 65.6 & & 6,579 & 70.5 & 247 & 64.2 & \\
\hline Black/African American & 2,930 & 11.7 & 101 & 13.5 & & 1,631 & 10.4 & 77 & 16.4 & \\
\hline Hispanic & 2,572 & 11.5 & 73 & 10.8 & & 1,961 & 12.7 & 76 & 11.5 & \\
\hline Other & 523 & 5.8 & 24 & 10.2 & & 523 & 6.4 & 21 & 7.8 & \\
\hline Education & & & & & & & & & & $*$ \\
\hline High school or less & 5,709 & 40.3 & 186 & 42.9 & & 4,215 & 41.1 & 123 & 32.0 & \\
\hline College or more & 8,217 & 59.7 & 227 & 57.1 & & 6,427 & 58.9 & 298 & 68.0 & \\
\hline Employment & & & & & $*$ & & & & & \\
\hline Employed & 7,259 & 55.7 & 228 & 63.3 & & 7,203 & 70.1 & 272 & 69.1 & \\
\hline Unemployed & 6,689 & 44.4 & 185 & 36.7 & & 3,467 & 29.9 & 148 & 30.9 & \\
\hline Survey Year & & & & & $* * *$ & & & & & $* * *$ \\
\hline 2000 & 3,794 & 28.4 & 86 & 20.1 & & 3,284 & 28.5 & 84 & 16.2 & \\
\hline 2005 & 3,379 & 25.8 & 85 & 21.6 & & 3,033 & 26.1 & 81 & 18.8 & \\
\hline 2010 & 3,734 & 25.0 & 91 & 22.8 & & 2,320 & 25.3 & 107 & 27.8 & \\
\hline 2015 & 3,075 & 20.9 & 151 & 35.5 & & 2,057 & 20.1 & 149 & 37.2 & \\
\hline State-level Same-sex Marriage Laws & & & & & $* *$ & & & & & $* * *$ \\
\hline $\begin{array}{l}\text { No legal recognition } \\
\text { Domestic partnership/civil union }\end{array}$ & 9,759 & 71.2 & 249 & 61.2 & & 7,805 & 72.0 & 254 & 61.6 & \\
\hline $\begin{array}{l}\text { option and/or recognition of } \\
\text { marriage in other states }\end{array}$ & 1,900 & 12.6 & 66 & 12.5 & & 1,351 & 12.5 & 53 & 10.2 & \\
\hline Statewide access to marriage & 2,308 & 16.2 & 98 & 26.3 & & 1,531 & 15.5 & 114 & 28.2 & \\
\hline
\end{tabular}

Notes. The combined dataset contained data from 29,571 respondents; sexual minority status could be categorized for 25,510 respondents. Valid percentages are listed; missing data was generally minimal. Unweighted cell sizes are presented, but prevalence estimates are weighted. Pearson chi-squared statistics are corrected for the survey design with the second-order Rao and Scott correction, converted into an F statistic. *p $<0.05$; $* * \mathrm{p}<0.01 ; * * * \mathrm{p}<0.001$

High-Intensity Drinking was constructed as any versus no instance of consuming 8 or more drinks in a single day in the past year. Inclusion of this measure was based on prior research suggesting an association between alcohol-related problems and consuming large amounts of alcohol at one time (Greenfield et al., 2014), as well as documenting sexual orientation disparities in high-intensity drinking among adults in the U.S. (Fish, 2019; Fish, Hughes, \& Russell, 2018).
Alcohol Use Disorder. Past-year alcohol use disorder was defined as endorsing symptoms in 2 or more of 11 domains, defined as at least mild severity in the 5th edition of the American Psychiatric Association's Diagnostic and Statistical Manual (American Psychiatric Association, 2013).

Marijuana Use was dichotomized as any versus no use in the past 12 months. 
Demographics and Other Covariates. Demographic measures included age (categorical), race/ethnicity, highest year of education, employment status, and children ages 17 or younger living in the household (see Table 1). Other covariates included survey year $(2000,2005,2010,2015)$ and a three-category measure of state laws regarding samesex marriage at the time of the interview (no legal recognition, domestic partnership/civil union available and/or recognition of marriage from other states, legalized same-sex marriage).

Table 2

Findings from Independent and Interaction Effects Models

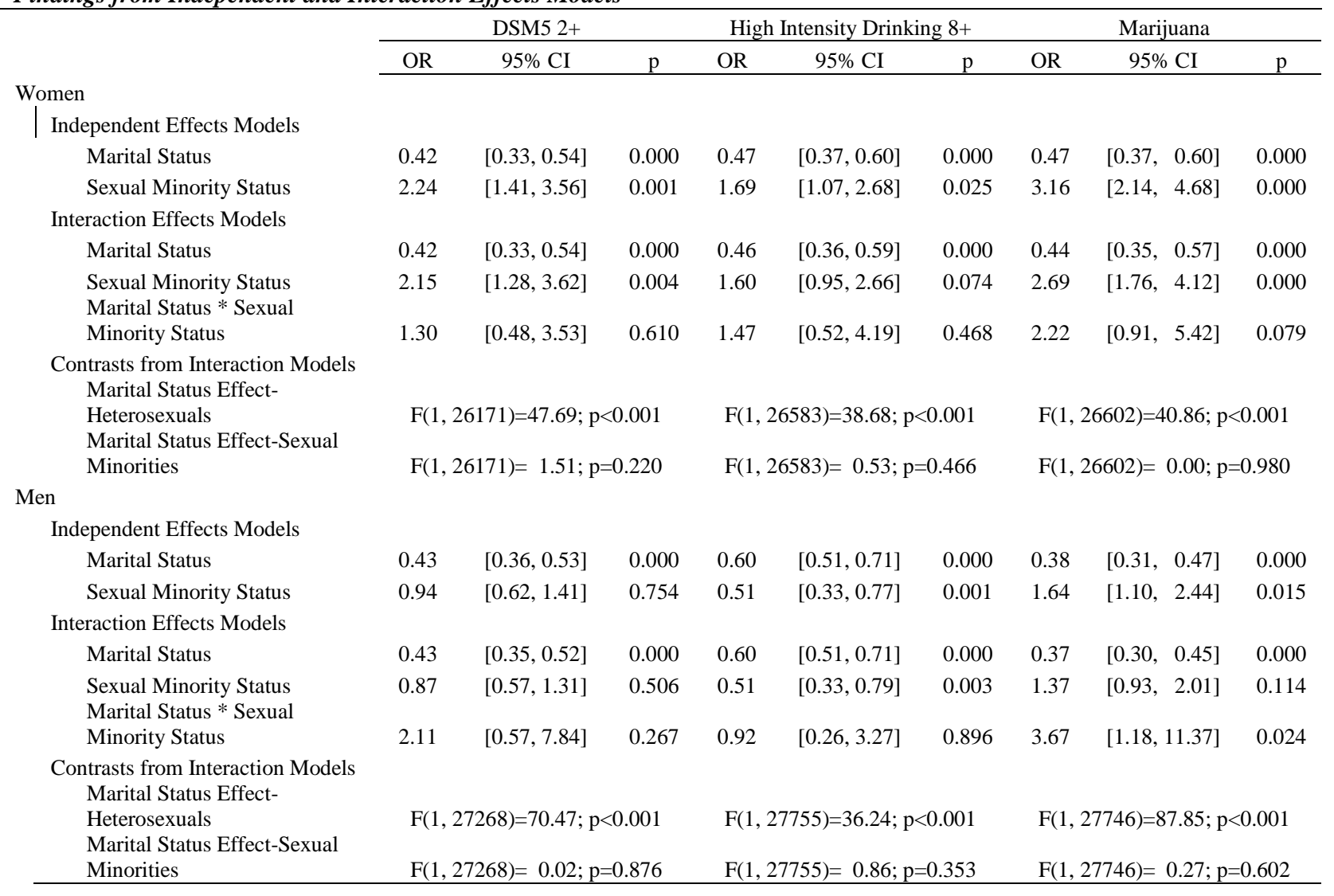

Notes. Models are weighted and adjust for age, children in the household, race/ethnicity, education, employment, survey year, and state-level same-sex marriage laws

\section{Statistical Analyses}

All analyses were conducted in Stata (version 15) using sample weights and variance estimation techniques that adjusted for the complex survey design. We first conducted multivariable, sex-stratified logistic regression analyses to test independent effects of marital and sexual minority status on outcomes, controlling for demographics and other covariates. We then ran sex-stratified models including an interaction between marital status and sexual minority status to examine differential effects of marital status. In these models, contrasts tested effects of marital status separately for each group (heterosexuals and sexual minorities). In addition to presenting model coefficients, we graphically display predictive margins for each of the four groups, stratified by sex.

Because some same-sex couples did not have access to legalized marriage at the time of data collection, we also ran sensitivity analyses to investigate how results might differ when including cohabiting with married individuals (compared to those who were legally separated, divorced, widowed, or never married). Sensitivity analysis results are reported for women and men separately.

\section{Results}

Women

Table 2 summarizes results from models examining the independent and interactive effects of marital status and sexual minority status on alcohol and marijuana use measures. In the independent effects model for women, being married significantly decreased odds of alcohol use disorder, high-intensity drinking, and marijuana use, whereas sexual minority status increased the odds of each substance use outcome. However, the interaction between marital status and sexual minority status was non-significant in all models. Contrasts showed the protective effect of marriage was significant for heterosexual women, but not for 
SMW. Table 3 displays the predicted probabilities (also see Figure 1) and average marginal effects (AME) of marriage for women by sexual identity. The AME of marriage for heterosexual women decreased the probability of harmful drinking and marijuana use by $4 \%-5 \%$. The AME of marriage for SMW (see Table 3 and Figure 1) showed a trend toward decreased prevalence of alcohol use disorder and high-intensity drinking, although confidence intervals around the adjusted prevalence estimates for SMW were quite large and overlapped among married and unmarried SMW. For SMW, there was no indication of a protective effect of marriage in relation to marijuana use (the AME of marriage for marijuana use among SMW was essentially zero).

Sensitivity analyses combining cohabiting women with married women did not change the overall findings. There were no differential effects of married/cohabiting partnership status by sexual identity among women (findings from independent and interactive effects models are available upon request from the corresponding author)

\section{Figure 1}

\section{Substance Use Predictive Margins by Gender, Sexual Identity, and Marital Status}

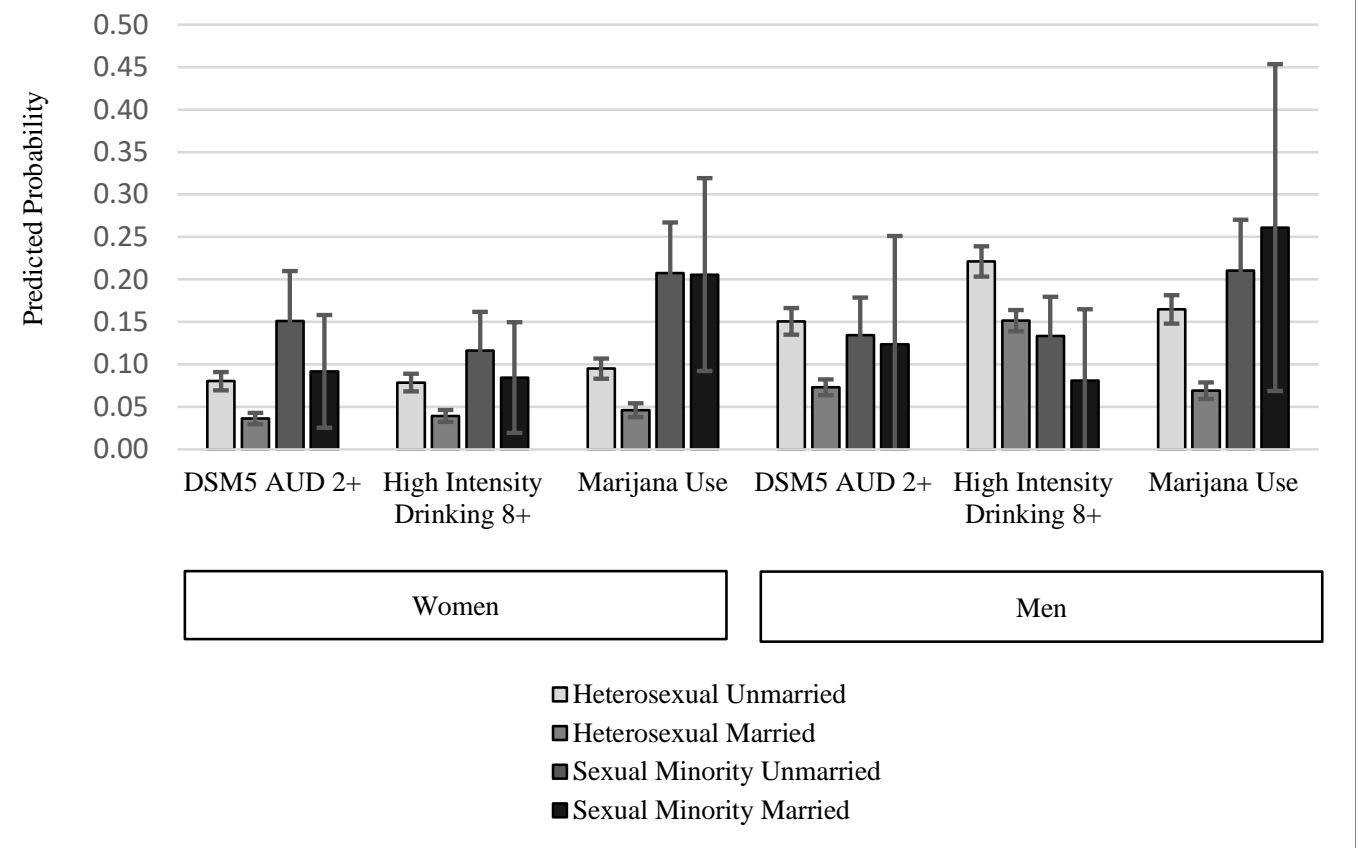

Men

In the independent effects model among men (see Table 2), being married significantly decreased the odds of all substance use outcomes. Sexual minority status was associated with lower odds of high-intensity drinking and greater odds of marijuana use; there was no association with alcohol use disorder. There was evidence of an interaction effect of marital status and sexual minority status on marijuana use (Finteraction $[1,27746]=6.31 ; \mathrm{p}=0.012$ ). Contrasts from interaction models showed the protective effects of marital status were significant for heterosexual men, but not for SMM. Table 3 displays the predicted probabilities (also see Figure 1) and average marginal effects (AME) of marriage for men. The AME of marriage for heterosexual men decreased the probability of both alcohol measures and marijuana use by $7 \%-10 \%$. Although the AME of marriage for SMM suggested a similar 5\% decrease in the probability of high-intensity drinking, the confidence intervals around the estimates overlapped among married and unmarried SMM. The small increase in the probability of marijuana use among married SMM was not significant, but the difference in comparison to the highly significant decrease in probability of use among married heterosexual men resulted in a statistically significant interaction effect.

Sensitivity analyses combining cohabiting and married men amplified differential effects of marital status. Among heterosexual men, the protective effect of being married/cohabitating was statistically significant, but it was not significant among SMM. Although the greater probability of harmful drinking and marijuana use among married/cohabitating SMM compared to unmarried SMM was not statistically significant (average marginal effects table available from the corresponding author), the divergent effects were large enough to create statistically significant interactive effects across all three substance use measures 
Table 3

Predicted Probabilities and Average Marginal Effects of Marriage by Gender and Sexual Identity

\begin{tabular}{|c|c|c|c|c|c|c|c|c|c|c|c|c|}
\hline & \multicolumn{4}{|c|}{ Heterosexual } & & & \multicolumn{4}{|c|}{ Sexual Minority } & \multirow[b]{3}{*}{ AME } & \multirow[b]{3}{*}{$\mathrm{p}$} \\
\hline & \multicolumn{2}{|c|}{ Unmarried } & \multicolumn{2}{|c|}{ Married } & \multirow[b]{2}{*}{ AME } & \multirow[b]{2}{*}{$\mathrm{p}$} & \multicolumn{2}{|c|}{ Unmarried } & \multicolumn{2}{|c|}{ Married } & & \\
\hline & Est & SE & Est & SE & & & Est & SE & Est & SE & & \\
\hline \multicolumn{13}{|l|}{ Women } \\
\hline DSM5 2+ & 0.08 & 0.01 & 0.04 & 0.00 & -0.04 & 0.000 & 0.15 & 0.03 & 0.09 & 0.03 & -0.06 & 0.185 \\
\hline High Intensity Drinking 8+ & 0.08 & 0.01 & 0.04 & 0.00 & -0.04 & 0.000 & 0.12 & 0.02 & 0.08 & 0.03 & -0.03 & 0.437 \\
\hline Marijuana Use & 0.10 & 0.01 & 0.05 & 0.00 & -0.05 & 0.000 & 0.21 & 0.03 & 0.21 & 0.06 & 0.00 & 0.980 \\
\hline \multicolumn{13}{|l|}{ Men } \\
\hline DSM5 2+ & 0.15 & 0.01 & 0.07 & 0.00 & -0.08 & 0.000 & 0.13 & 0.02 & 0.12 & 0.07 & -0.01 & 0.872 \\
\hline High Intensity Drinking $8+$ & 0.22 & 0.01 & 0.15 & 0.01 & -0.07 & 0.000 & 0.13 & 0.02 & 0.08 & 0.04 & -0.05 & 0.280 \\
\hline Marijuana Use & 0.16 & 0.01 & 0.07 & 0.00 & -0.10 & 0.000 & 0.21 & 0.03 & 0.26 & 0.10 & 0.05 & 0.621 \\
\hline
\end{tabular}

Notes. Each estimate (Est) can be interpreted as the adjusted prevalence of substance use outcomes among unmarried and married heterosexual and sexual minority respondents. The average marginal effect (AME) of being married represents the difference between the estimates for unmarried and married respondents. 95\% confidence intervals based on standard errors (SE) for the estimates are depicted in Figure 1.

\section{Discussion}

Our findings support prior research documenting robust protective effects of marriage against alcohol use disorder, heavy drinking, and marijuana use among heterosexual women and men, but not among sexual minorities. Interaction tests did not find significant differences in alcohol measures by marital status and sexual identity. However, although marijuana outcomes did not differ between heterosexual women and SMW, we found evidence of differential effects of marriage by sexual identity status for marijuana use by men. Sensitivity analyses including cohabiting with married men amplified differences in the effects of marriage between heterosexuals and SMM for drinking outcomes in a similar way, showing significant decreases among heterosexual men but a trend toward increased use among SMM.

There are several reasons marijuana use among married SMM might be higher than among their non-married SMM peers and their married heterosexual counterparts. First, higher rates of marijuana use and heavier drinking before marriage predict marijuana use after marriage (Homish, Leonard, \& Cornelius, 2007). Given robust findings to date that marijuana use is significantly more prevalent among sexual minorities compared to heterosexuals (Boyd et al., 2019), continuation of heavier marijuana use may be particularly salient for married SMM compared to married heterosexual men. Furthermore, concordance in health behaviors among same-sex couples is greater than among heterosexual couples (Holway, Umberson, \& Donnelly, 2018), so if a SMM uses marijuana, his spouse is more likely to use as well. Differential effects of marijuana use among women did not reach significance (only marginally significant interaction test) in the current study. The difference by sex might be explained in part by sex differences in how women and men influence their spouse's behavior. Women, regardless of their sexual identity, appear more likely than their male counterparts to use both direct and indirect strategies to positively influence their spouse's health behaviors (Umberson et al., 2018); thus, it is possible that SMW may benefit from marriage more than SMM. Additional research is needed with larger samples to determine whether this finding replicates and to better understand underlying reasons for potential differences between men and women.

Although findings should be interpreted with caution given large confidence intervals for SMM and SMW in the current study, the absence of a robust protective effect of marriage against alcohol use disorders among SMW and SMM in the current study may be due to the continued impact (after marriage) of minority stress on sexual minorities. Other studies (Du Bois et al, 2019; Kahle et al, 2020) found little evidence of a protective effect for marriage in relation to heavier drinking among married sexual minorities. As DuBois and colleagues point out, it is possible that being married may not fully buffer sexual minorities against the negative health impact of continued systemic discrimination and marginalization. Research verifies that same-sex married couples continue to experience minority stress as a result of their stigmatized statuses as sexual minority individuals and as a sexual minority couple (LeBlanc et al., 2018; Rostosky \& Riggle, 2016). Furthermore, a recent U.S. study found mental health disparities as a whole have persisted over time in the U.S., despite legalization of samesex marriage, and health disparities among young sexual minorities actually worsened from 2013 to 2016 (Hsieh, 2019). 
In addition to minority stress, other factors may influence substance use among sexual minorities. Social psychological theories related to perceived norms and normative behavior may be important for understanding disparities in risk by sexual identity (Boyle, LaBrie, \& Omoto, 2020; Boyle, LaBrie, \& Witkovic, 2016; Cochran, Grella, \& Mays, 2012). For example, research suggests perceived norms are reliable predictors of sexual minority substance use and sexual minorities overestimate the alcohol and drug use of peers (Boyle et al., 2020; Boyle et al., 2016; Cochran et al., 2012). Disparities in substance use also might be explained, in part, by differences in family and relationship structures. Role socialization theory suggests that changes in roles, such as parenting, are associated with reductions in alcohol and drug use, and these roles may differ by sexual identity (Hughes, 2005; Umberson \& Karas Montez, 2010). Consistent with this theory, research suggests that both relationship status and having children under the age of 18 are important protective factors across sexual identity groups (Hughes, Szalacha, \& McNair, 2010). It is worth noting that in the current study a majority of heterosexual study participants were married and had children, but the opposite was true for sexual minorities. Other differences in cultural and subcultural norms may influence potential relationships between marital status and substance use as well. For example, sexual and gender minority communities often embrace diverse conceptualizations of intimacy and respect varied relationship structures, which are more inclusive than traditional paradigms that privilege married, monogamous, heterosexual, and biological (rather than chosen family/community) relationships (Hammack, Frost, \& Hughes, 2019). Measures of relationship status used in the current (and many other studies) may not adequately capture the diversity of intimate and supportive relationships in sexual and gender minority communities and, consequently, may not accurately characterize how those different relationships might influence health behaviors.

Findings should be interpreted in the context of study limitations. Data were collected largely before marriage was legalized for same-sex couples nationally; future studies are needed to monitor the potential differences in the effects of marriage in the new legal environment over time. Another important limitation is our inability to disaggregate bisexual and gay/lesbian respondents. This is especially true for SMW, given robust findings that bisexual women are more likely than lesbian women to engage in hazardous drinking (Green \& Feinstein, 2012; Hughes et al., 2020; McCabe et al., 2009). Previous research also has found differences in the associations of relationship status with hazardous drinking among bisexual and lesbian women (Veldhuis, Hughes, Drabble, Wilsnack, \& Matthews, 2020).

Additionally, the NAS did not ask about the sex or sexual identity of the respondent's spouse, making it impossible to control for such differences. However, previous research using a large and diverse volunteer sample of SMW suggests sexual identity may be a more robust predictor of relationships status differences in alcohol outcomes than sex of partner (Veldhuis et al., 2019). We also were unable to assess concordance in alcohol or marijuana among couples, a potentially important factor in substance use differences by sexual identity. Furthermore, the data were gathered over a 15 -year period in which access to legalized marriage and social acceptance of LGBT people have been changing. Although we controlled for survey year and state laws regarding same-sex marriage at the time of the interview in our analyses, it was not possible to fully control for contextual changes that may have influenced respondent disclosure of sexual identity, classification of relationship status, or other responses over time. As mentioned earlier, the confidence intervals for sexual minority estimates were large, likely due to relatively small sample sizes. Future studies using strategies to over-sample sexual minorities are needed. Finally, the current study did not include measures of sexual minority stress (e.g., experiences of discrimination because of sexual minority status) or resiliency factors that may moderate the association between relationship status and substance use outcomes (e.g., level of family support and community support for sexual minority people in committed or married relationships). Studies are needed that examine both risk and protective factors that may differentially influence associations between relationship status and health outcomes among sexual minorities relative to heterosexuals.

Despite these limitations, this study underscores the importance of research on predictors of behavioral health outcomes among married sexual minorities. Future studies are needed that account for factors that influence the protective effect of marriage, such as partner sex/gender, concordance/discordance of substance use behaviors, social support, couple-level sexual identity disclosure, and structural stigma. Inclusion of such measures is important given findings from qualitative studies suggesting that the individual experience of national legal marriage recognition may be influenced by both interpersonal factors, such as familial rejection of same-sex marriage, as well as societal factors, such as inconsistent legal protections against discrimination for sexual and gender minorities (Lannutti, 2011a; Riggle, Drabble, Veldhuis, Wootton, \& Hughes, 2018; Wootton et al., 2019). Because marriage may be less consistently protective against hazardous drinking and marijuana use among sexual minorities than heterosexuals, studies are needed to better understand disparities in substance use across both sexual identity and relationship statuses and to identify factors that contribute to minority stress in these different groups.

\section{References}

American Psychiatric Association. (2013). Diagnostic and statistical manual of mental disorders, 5th Edition. Arlington, VA: American Psychiatric Association.

Arriaga, A. S., \& Parent, M. C. (2019). Partners and prejudice: Bisexual partner gender and experiences of binegativity from heterosexual, lesbian, and gay people. Psychology of Sexual Orientation and Gender Diversity, 6(3), 382-391. doi:https://doi.org/10.1037/sgd0000337

Badgett, M. (2011). Social inclusion and the value of marriage equality in Massachusetts and the Netherlands. Journal of Social Issues, 67(2), 316-334. doi: https://doi.org/10.1111/j.1540-4560.2011.01700.x 
Blair, S., \& Menasco, M. A. (2016). Gender differences in substance use across marital statuses. International Journal of Criminology and Sociology, 5, 1-13. doi: http://dx.doi.org/10.6000/1929-4409.2016.05.01

Bosley-Smith, E. R., \& Reczek, C. (2018). Before and after "I Do": Marriage processes for mid-life gay and lesbian married couples. Journal of Homosexuality, 65(14), 1985-2004. doi: https://doi.org/10.1080/00918369.2017.1423213

Boyd, C. J., Veliz, P. T., Stephenson, R., Hughes, T. L., \& McCabe, S. E. (2019). Severity of alcohol, tobacco, and drug use disorders among sexual minority individuals and their "not sure" counterparts. LGBT Health, 6(1), 15-22. doi: https://doi.org/10.1089/lgbt.2018.0122

Boyle, S. C., LaBrie, J. W., \& Omoto, A. M. (2020). Normative substance use antecedents among sexual minorities: A scoping review and synthesis. Psychology of Sexual Orientation and Gender Diversity, 7(2), 117131. doi: https://doi.org/10.1037/sgd0000373

Boyle, S. C., LaBrie, J. W., \& Witkovic, Y. D. (2016). Do lesbians overestimate alcohol use norms? Exploring the potential utility of personalized normative feedback interventions to reduce high-risk drinking in Southern California lesbian communities. Journal of Gay \& Lesbian Social Services: The Quarterly Journal of Community \& Clinical Practice, 28(3), 179-194. doi: https://doi.org/10.1080/10538720.2016.1190677

Carpenter, C., Eppink, S. T., Gonzales Jr, G., \& McKay, T. (2018). Effects of access to legal same-sex marriage on marriage and health: Evidence from BRFSS. doi: https://doi.org/10.3386/w24651

Cochran, S. D., Grella, C. E., \& Mays, V. M. (2012). Do substance use norms and perceived drug availability mediate sexual orientation differences in patterns of substance use? Results from the California Quality of Life Survey II. Journal of Studies on Alcohol and Drugs, 73(4), 675-685.

de Lira, A. N., \& de Morais, N. A. (2018). Resilience in Lesbian, Gay, and Bisexual (LGB) populations: An integrative literature review. Sexuality Research and Social Policy, 15(3), 272-282. doi: https://doi.org/10.1007/s13178-017-0285-x

DeMaio, T. J., Bates, N., \& O'Connell, M. (2013). Exploring measurement error issues in reporting of same-sex couples. Public Opinion Quarterly, 77(S1), 145-158. doi: https://doi.org/10.1093/poq/nfs066

Demant, D., Hides, L., Kavanagh, D. J., White, K. M., Winstock, A. R., \& Ferris, J. (2016). Differences in substance use between sexual orientations in a multicountry sample: findings from the Global Drug Survey 2015. Journal of Public Health, 39(3), 532-541.

Donnelly, R., Robinson, B. A., \& Umberson, D. (2019). Can spouses buffer the impact of discrimination on depressive symptoms? An examination of same-sex and different-sex marriages. Society and Mental Health, 9(2), 192-210. doi: https://doi.org/10.1177/2156869318800157

Drabble, L. A., Mericle, A. A., Karriker-Jaffe, K. J., \& Trocki, K. F. (2020). Harmful drinking, tobacco, and marijuana use in the 2000-2015 National Alcohol Surveys: Examining differential trends by sexual identity. Substance Abuse, (online in advance of print),
$1-12$.

doi: https://doi.org/10.1080/08897077.2019.1709251

Drabble, L. A., Wootton, A. R., Veldhuis, C. B., Perry, E., Riggle, E. D., Trocki, K. F., \& Hughes, T. L. (2020). It's complicated: The impact of marriage legalization among sexual minority women and gender diverse individuals in the United States. Psychology of Sexual Orientation and Gender Diversity, (online in advance of print), doi: https://doi.org/10.1037/sgd0000375

Du Bois, S. N., Legate, N., \& Kendall, A. D. (2019). Examining partnership-health associations among lesbian women and gay men using population-level data. LGBT Health, 6(1), 23-33. doi: https://doi.org/10.1089/lgbt.2018.0158

Ducharme, J. K., \& Kollar, M. M. (2012). Does the "marriage benefit" extend to same-sex union?: Evidence from a sample of married lesbian couples in Massachusetts. Journal of Homosexuality, 59(4), 580591.

doi: https://doi.org/10.1080/00918369.2012.665689

Dyar, C., Feinstein, B. A., \& London, B. (2014). Dimensions of sexual identity and minority stress among bisexual women: The role of partner gender. Psychology of Sexual Orientation and Gender Diversity, 1(4), 441-451.

Eliason, M. J., Burke, A., van Olphen, J., \& Howell, R. (2011). Complex interactions of sexual identity, sex/gender, and religious/spiritual identity on substance use among college students. Sexuality Research and Social Policy, 8(2), 117-125.

Feinstein, B. A., Latack, J. A., Bhatia, V., Davila, J., \& Eaton, N. R. (2016). Romantic relationship involvement as a minority stress buffer in gay/lesbian versus bisexual individuals. Journal of Gay \& Lesbian Mental Health, 20(3), 237-257. doi: https://doi.org/10.1080/19359705.2016.1147401

Fish, J. N. (2019). Sexual orientation-related disparities in high-intensity binge drinking: findings from a nationally representative sample. LGBT Health, 6(5), 242-249. doi: https://doi.org/10.1089/lgbt.2018.0244

Fish, J. N., Hughes, T. L., \& Russell, S. T. (2018). Sexual identity differences in high-intensity binge drinking: findings from a US national sample. Addiction, 113(4), 749-758.

Frost, D. M. (2017). The benefits and challenges of health disparities and social stress frameworks for research on sexual and gender minority health. Journal of Social Issues, $\quad 73(3), \quad 462-476 . \quad$ doi: https://doi.org/10.1111/josi.12226

Frost, D. M., \& Gola, K. A. (2015). Meanings of intimacy: A comparison of members of heterosexual and same-sex couples. Analyses of Social Issues and Public Policy, 15(1), 382-400. doi: https://doi.org/10.1111/asap.1207

Frost, D. M., LeBlanc, A. J., de Vries, B., Alston-Stepnitz, E., Stephenson, R., \& Woodyatt, C. (2017). Couple-level minority stress: An examination of same-sex couples' unique experiences. Journal of Health and Social Behavior, 58(4), 455-472.

Goldsen, J., Bryan, A. E., Kim, H.-J., Muraco, A., Jen, S., \& Fredriksen-Goldsen, K. I. (2017). Who says I Do: The changing context of marriage and health and quality of life for LGBT older adults. The Gerontologist, 57(suppl 1), S50-S62. 
Gonzales, G., Przedworski, J., \& Henning-Smith, C. (2016). Comparison of health and health risk factors between lesbian, gay, and bisexual adults and heterosexual adults in the United States: results from the National Health Interview Survey. JAMA Internal Medicine, 176(9), 1344-1351. https://doi.org/10.1001/jamainternmed.2016.3432

Green, K. E., \& Feinstein, B. A. (2012). Substance use in lesbian, gay, and bisexual populations: An update on empirical research and implications for treatment. Psychology of Addictive Behaviors, 26(2), 265-278. doi: https://doi.org/10.1037/a0025424

Greenfield, T. K., Ye, Y., Bond, J., Kerr, W. C., Nayak, M. B., Kaskutas, L. A., . . Kranzler, H. R. (2014). Risks of alcohol use disorders related to drinking patterns in the US general population. Journal of Studies on Alcohol and Drugs, 75(2), 319-327.

Hammack, P. L., Frost, D. M., \& Hughes, S. D. (2019). Queer intimacies: A new paradigm for the study of relationship diversity. The Journal of Sex Research, 56(4-5), 556-592. doi: https://doi.org/10.1080/00224499.2018.1531281

Hatzenbuehler, M. L. (2009). How does sexual minority stigma "get under the skin"? A psychological mediation framework. Psychological Bulletin, 135(5), 707-730. doi: https://doi.org/10.1037/a0016441

Hayfield, N., Campbell, C., \& Reed, E. (2018). Misrecognition and managing marginalisation: Bisexual people's experiences of bisexuality and relationships. Psychology \& Sexuality, 9(3), 221-236. doi: https://doi.org/10.1080/19419899.2018.1470106

Herek, G. M. (2006). Legal recognition of same-sex relationships in the United States: A social science perspective. American Psychologist, 61(6), 607-621. doi: http://doi.org/10.1037/0003-066X.61.6.607

Holway, G. V., Umberson, D., \& Donnelly, R. (2018). Health and health behavior concordance between spouses in same-sex and different-sex marriages. Social $\begin{array}{lrrr}\text { currents, } & 5(4), & 319-327 .\end{array}$ https://doi.org/10.1177/2329496517734570

Homish, G. G., Leonard, K. E., \& Cornelius, J. R. (2007). Predictors of marijuana use among married couples: the influence of one's spouse. Drug and Alcohol Dependence, 91(2-3), 121-128. doi: https://doi.org/10.1016/j.drugalcdep.2007.05.014

Hsieh, N. (2019). Mental health disparities by sexual orientation in the US: Current patterns and recent trends. EurAmerica, 49(2), 201-244.

Hsieh, N., \& Liu, H. (2019). Bisexuality, union status, and gender composition of the couple: Reexamining marital advantage in health. Demography, 56(5), 1791-1825. doi: https://doi.org/10.1007/s13524-019-00813-2

Hughes, T., Szalacha, L. A., \& McNair, R. (2010). Substance abuse and mental health disparities: Comparisons across sexual identity groups in a national sample of young Australian Women. Social Science \& Medicine, 71(4), 824-831.

Hughes, T. L. (2005). Alcohol use and alcohol-related problems in lesbians and gay men. Annual Review of Nursing Research, 23, 283-325.

Hughes, T. L., Szalacha, L. A., Johnson, T. P., Kinnison, K. E., Wilsnack, S. C., \& Cho, Y. (2010). Sexual victimization and hazardous drinking among heterosexual and sexual minority women. Addictive Behaviors, 35(12), 1152-1156. doi: https://doi.org/10.1016/j.addbeh.2010.07.004

Hughes, T. L., Veldhuis, C. B., Drabble, L. A., \& Wilsnack, S. C. (2020). Substance use among sexual minority women: A global scoping review. PLOS One, 15(3), (online in advance of print). doi: https://doi.org/10.1371/journal.pone.0229869

Hughes, T. L., Wilsnack, S. C., \& Kantor, L. (2016). The influence of gender and sexual orientation on alcohol use and alcohol-related problems: Toward a global perspective. Alcohol Research: Current Reviews, 38(1), 121-132.

Hughes, T. L., Wilsnack, S. C., \& Kristjanson, A. F. (2015). Substance use and related problems among US women who identify as mostly heterosexual. BMC Public Health, 15(1), 803. doi: https://doi.org/10.1186/s12889015-2143-1

Jang, B. J., Patrick, M. E., \& Schuler, M. S. (2018). Substance use behaviors and the timing of family formation during young adulthood. Journal of Family Issues, 39(5), 1396-1418. doi: https://doi.org/10.1177/0192513X17710285

Kahle, E. M., Veliz, P., McCabe, S. E., \& Boyd, C. J. (2020). Functional and structural social support, substance use and sexual orientation from a nationally representative sample of US adults. Addiction, 115(3), 546-558. doi: https://doi.org/10.1111/add.14819

Kerridge, B. T., Pickering, R. P., Saha, T. D., Ruan, W. J., Chou, S. P., Zhang, H., . . . Hasin, D. S. (2017). Prevalence, sociodemographic correlates and DSM-5 substance use disorders and other psychiatric disorders among sexual minorities in the United States. Drug and Alcohol Dependence, 170, 82-92. doi: https://doi.org/10.1016/j.drugalcdep.2016.10.038

King, M., Semlyen, J., Tai, S. S., Killaspy, H., Osborn, D., Popelyuk, D., \& Nazareth, I. (2008). A systematic review of mental disorder, suicide, and deliberate self harm in lesbian, gay and bisexual people. $B M C$ Psychiatry, 8, 1-17.

Lambe, J., Cerezo, A., \& O'Shaughnessy, T. (2017). Minority stress, community involvement, and mental health among bisexual women. Psychology of Sexual Orientation and Gender Diversity, 4(2), 218-226. doi: https://doi.org/10.1037/sgd0000222

Lannutti, P. J. (2005). For better or worse: Exploring the meanings of same-sex marriage within the lesbian, gay, bisexual and transgendered community. Journal of Social and Personal Relationships, 22(1), 5-18. doi: https://doi.org/10.1177/0265407505049319

Lannutti, P. J. (2008). Attractions and obstacles while considering legally recognized same-sex marriage. Journal of GLBT Family Studies, 4(2), 245-264.

Lannutti, P. J. (2011a). Examining communication about marriage amendments: Same-sex couples and their extended social networks. Journal of Social Issues, 67(2), 264-281. doi: https://doi.org/10.1111/j.15404560.2011.01697.x

Lannutti, P. J. (2011b). Security, recognition, and misgivings: Exploring older same-sex couples' experiences of legally recognized same-sex marriage. 
Journal of Social and Personal Relationships, 28(1), 6482. doi: https://doi.org/10.1177/0265407510386136

Lannutti, P. J. (2014). Experiencing same-sex marriage: Individual, couples, and social networks. New York: Peter Lang.

LeBlanc, A. J., \& Frost, D. M. (2019). Couple-level minority stress and mental health among people in same-sex relationships: extending minority stress theory. Society and Mental Health, doi: https://doi.org/10.1177/2156869319884724

LeBlanc, A. J., Frost, D. M., \& Wight, R. G. (2015). Minority stress and stress proliferation among same-sex and other marginalized couples. Journal of Marriage and Family, 77(1), 40-59.

Lewis, R. J., Mason, T. B., Winstead, B. A., Gaskins, M., \& Irons, L. B. (2016). Pathways to hazardous drinking among racially and socioeconomically diverse lesbian women: Sexual minority stress, rumination, social isolation, and drinking to cope. Psychology of Women Quarterly, 40(4), 564-581. doi: https://doi.org/10.1177/0361684316662603

Lewis, R. J., Winstead, B. A., Lau-Barraco, C., \& Mason, T. B. (2017). Social factors linking stigma-related stress with alcohol use among lesbians. Journal of Social Issues, 73(3), 545-562. doi: https://doi.org/10.1111/josi.12231

Li, Q., Wilsnack, R., Wilsnack, S., \& Kristjanson, A. (2010). Cohabitation, gender, and alcohol consumption in 19 countries: A multilevel analysis. Substance Use \& Misuse, 45(14), 2481-2502. doi: https://doi.org/10.3109/10826081003692106

Liang, W., \& Chikritzhs, T. (2012). Brief report: Marital status and alcohol consumption behaviours. Journal of Substance Use, 17(1), 84-90. doi: https://doi.org/10.3109/14659891.2010.538463

MacIntosh, H., Reissing, E. D., \& Andruff, H. (2010). Samesex marriage in Canada: The impact of legal marriage on the first cohort of gay and lesbian Canadians to wed. Canadian Journal of Human Sexuality, 19(3), 79-90.

McCabe, S. E., Bostwick, W. B., Hughes, T. L., West, B. T., \& Boyd, C. J. (2010). The relationship between discrimination and substance use disorders among lesbian, gay, and bisexual adults in the United States. American Journal of Public Health, 100(10), 19461952. doi: https://doi.org/10.2105/ajph.2009.163147

McCabe, S. E., Hughes, T. L., Bostwick, W. B., West, B. T., \& Boyd, C. J. (2009). Sexual orientation, substance use behaviors and substance dependence in the United States. Addiction, 104(8), 1333-1345. doi: https://doi.org/10.1111/j.1360-0443.2009.02596.x

McCabe, S. E., West, B. T., Strobbe, S., \& Boyd, C. J. (2018). Persistence/recurrence and remission from DSM-5 substance use disorders in the United States: Substance-specific and substance-aggregated correlates. Journal of Substance Abuse Treatment. 93, 38-48. doi: https://doi.org/10.1016/j.jsat.2018.07.012

Meyer, I. H. (2003). Prejudice, social stress, and mental health in lesbian, gay, and bisexual populations: Conceptual issues and research evidence. Psychological Bulletin, 129(5), 674-697. doi: https://doi.org/10.1037/0033-2909.129.5.674
Meyer, I. H., \& Frost, D. (2013). Minority stress and the health of sexual minorities. In C. J. Patterson \& A. R. D'Augelli (Eds.), Handbook of psychology and sexual orientation (pp. 252-266). New York: Oxford University Press.

Midanik, L. T., Drabble, L., Trocki, K., \& Sell, R. (2006). Sexual orientation and alcohol use: Identity versus behavior measures. Journal of Lesbian, Gay, Bisexual, and Transgender Health Research, 3(1), 25-35. doi: https://doi.org/10.1300/J463v03n01_04

Molina, Y., Marquez, J. H., Logan, D. E., Leeson, C. J., Balsam, K. F., \& Kaysen, D. L. (2015). Current intimate relationship status, depression, and alcohol use among bisexual women: The mediating roles of bisexualspecific minority stressors. Sex Roles, 73(1-2), 43-57.

Ocobock, A. (2018). Status or access? The impact of marriage on lesbian, gay, bisexual, and queer community change. Journal of Marriage and Family, 80(2), 367382. doi: https://doi.org/10.1111/jomf.12468

Ogolsky, B. G., Monk, J. K., Rice, T. M., \& Oswald, R. F. (2019a). As the states turned: Implications of the changing legal context of same-sex marriage on wellbeing. Journal of Social and Personal Relationships, 36(10), 3219-3238. doi: https://doi.org/10.1177/0265407518816883

Ogolsky, B. G., Monk, J. K., Rice, T. M., \& Oswald, R. F. (2019b). Personal well-being across the transition to marriage equality: A longitudinal analysis. Journal of Family Psychology: JFP: Journal of the Division of Family Psychology of the American Psychological Association (Division 43), 33(4), 442-432. doi: https://doi.org/10.1037/fam0000504

Ramos, C., Goldberg, N. G., \& Badgett, M. (2009). The effects of marriage equality in Massachusetts: A survey of the experiences and impact of marriage on same-sex couples. Retrieved from Los Angeles, CA: https://escholarship.org/uc/item/9dx6v3kj

Reczek, C., Liu, H., \& Spiker, R. (2014). A population-based study of alcohol use in same-sex and different-sex unions. Journal of Marriage and Family, 76(3), 557572. doi: https://doi.org/10.1111/jomf.12113

Reczek, C., Liu, H., \& Spiker, R. (2017). Self-rated health at the intersection of sexual identity and union status. Social Science Research, 63, 242-252. doi: https://doi.org/10.1016/j.ssresearch.2016.09.013

Reczek, C., Pudrovska, T., Carr, D., Umberson, D., \& Thomeer, M. B. (2016). Marital histories and heavy alcohol use among older adults. Journal of Health and Social Behavior, 57(1), 77-96. doi: https://doi.org/10.1177/0022146515628028

Riggle, E. D., Rostosky, S. S., \& Horne, S. G. (2010). Psychological distress, well-being, and legal recognition in same-sex couple relationships. Journal of Family $\begin{array}{lll}\text { Psychology, } & 24(1), & \text { 82-86. doi: }\end{array}$ https://doi.org/10.1037/a0017942

Riggle, E. D., Wickham, R. E., Rostosky, S. S., Rothblum, E. D., \& Balsam, K. F. (2017). Impact of civil marriage recognition for long-term same-sex couples. Sexuality Research and Social Policy, 14(2), 223-232.

Riggle, E. D. B., Drabble, L., Veldhuis, C. B., Wootton, A., \& Hughes, T. L. (2018). The impact of marriage equality on sexual minority women's relationships with their 
families of origin. Journal of Homosexuality, 65(9), 1190-1206. doi: https://doi.org/10.1080/00918369.2017.1407611

Rostosky, S. S., \& Riggle, E. D. (2016). Same-sex relationships and minority stress. Current Opinion in Psychology, 13, 29-38. doi: https://doi.org/10.1016/j.copsyc.2016.04.011

Rostosky, S. S., Riggle, E. D., Rothblum, E. D., \& Balsam, K. F. (2016). Same-sex couples' decisions and experiences of marriage in the context of minority stress: Interviews from a population-based longitudinal study. Journal of Homosexuality, 63(8), 1019-1040. doi: https://doi.org/10.1080/00918369.2016.1191232

Sabia, J. J., Wooden, M., \& Nguyen, T. T. (2018). Sexual identity, same-same relationships, and health dynamics: New evidence from Australia. Economics \& Human Biology, 30, 24-36. doi: https://doi.org/10.1016/j.ehb.2018.02.005

Shulman, J. L., Gotta, G., \& Green, R.-J. (2012). Will marriage matter? Effects of marriage anticipated by same-sex couples. Journal of Family Issues, 33(2), 158181. doi: https://doi.org/10.1177/0192513x11406228

Spiker, R., Reczek, C., \& Liu, H. (2017). Activity limitation disparities by sexual minority status, gender, and union status. In M. Hoque, B. Pecotte \& M. McGehee (Eds.), Applied demography and public health in the 21st century (pp. 183-200). Cham: Springer.

Tatum, A. K. (2017). The interaction of same-sex marriage access with sexual minority identity on mental health and subjective wellbeing. Journal of Homosexuality, 64(5), 638-653. doi: https://doi.org/10.1080/00918369.2016.1196991

Umberson, D., Donnelly, R., \& Pollitt, A. M. (2018). Marriage, social control, and health behavior: A dyadic analysis of same-sex and different-sex couples. Journal of Health and Social Behavior, July 2018 (advance of print). doi: http://doi.org/10.1177/0022146518790560

Umberson, D., \& Karas Montez, J. (2010). Social relationships and health: A flashpoint for health policy. Journal of Health and Social Behavior, 51(1_suppl), S54-S66. doi: https://doi.org/10.1177/0022146510383501

Umberson, D., \& Kroeger, R. A. (2016). Gender, marriage, and health for same-sex and different-sex couples: The future keeps arriving. In S. M. McHale, V. King, J. Van Hook, \& A. Booth (Eds.), Gender and Couple Relationships (Vol. National Symposium on Family Issues, Vol 6, pp. 189-213). Switzerland: Springer International.

Veldhuis, C. B., Hughes, T. L., Drabble, L., Wilsnack, S., Riggle, E., \& Rostosky, S. S. (2019). Relationship status and drinking-related outcomes in a community sample of lesbian and bisexual women. Journal of Social and Personal Relationships, 36(1), 244-268. doi: https://doi.org/10.1177/0265407517726183

Veldhuis, C. B., Hughes, T. L., Drabble, L. A., Wilsnack, S. C., \& Matthews, A. K. (2020). Do relationships provide the same levels of protection against heavy drinking for lesbian and bisexual women? An intersectional approach. Psychology of Sexual Orientation and Gender Diversity. doi:
Whitton, S. W., Dyar, C., Newcomb, M. E., \& Mustanski, B. (2018). Romantic involvement: A protective factor for psychological health in racially-diverse young sexual minorities. Journal of Abnormal Psychology, 127(3), 265-275. doi: https://doi.org/10.1037/abn0000332

Wienke, C., \& Hill, G. J. (2008). Does the "marriage benefit" extend to partners in gay and lesbian relationships? Evidence from a random sample of sexually active adults. Journal of Family Issues, 30(2), 259-289. doi: https://doi.org/10.1177/0192513X08324382

Wight, R. G., LeBlanc, A. J., \& Badgett, M. V. L. (2013). Same-sex legal marriage and psychological well-being: Findings from the California Health Interview Survey. American Journal of Public Health, 103(2), 339-346. doi: https://doi.org/10.2105/AJPH.2012.301113

Williams, M. E., \& Fredriksen-Goldsen, K. I. (2014). Samesex partnerships and the health of older adults. Journal of Community Psychology, 42(5), 558-570.

Wootton, A. R., Drabble, L. A., Riggle, E. D., Veldhuis, C. B., Bitcon, C., Trocki, K. F., \& Hughes, T. L. (2019). Impacts of marriage legalization on the experiences of sexual minority women in work and community contexts. Journal of GLBT Family Studies, 15(3), 211234.

doi https://doi.org/10.1080/1550428X.2018.1474829 